\title{
A screening method for periodontal disease
}

\author{
Solenn HOURDIN, Dominique GLEZ, \\ Gilles GAGNOT, Olivier SOREL, Sylvie JEANNE
}

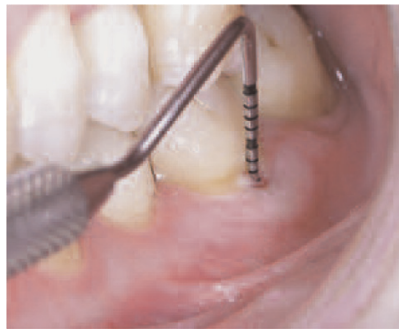

\section{SUMMARY}

The objective of this article is to offer a simplified and reasonable approach for periodontal disease screening that should be a mandatory part of each and every oral examination. The main purpose of this examination is to answer the question of whether or not there are any infection sites that require periodontal management. This assessment has three parts: the initial patient interview (medical history), the clinical oral examination and the radiological examination. Using a periodontal probe, the dentist should place a high priority on performing PD screening and it should be done systematically and routinely during every consultation.

Orthodontists and dentists are both licensed to perform this examination. After this examination, the practitioner can make a diagnosis, initiate periodontal management of the patient or refer the patient to an appropriate specialist.

$P D$ screening should be repeated before orthodontic treatment or before any functional rehabilitation in order to maintain periodontal stability.

\section{KEY WORDS}

\author{
Screening, \\ Periodontal disease, \\ Multi-disciplinary, \\ Probing measurement.
}

Periodontal disease is an infectious pathology characterized by an inflammation. Among the progressive forms of this disease, the pathognomonic or hallmark sign is the periodontal pocket: an increase in the depth of gingival sulcus greater than $3 \mathrm{~mm}$ with apical displacement of the gingival attachment. The insidious

Address for correspondence:

S. HOURDIN,

Faculté de chirurgie dentaire

Département de Parodontologie,

Département d'Orthodontie,

Université de Rennes,

2, av. du Pr Léon Bernard (Bât 15)

35043 Rennes cedex.

solennhourdin.rennes@orange.fr

Article available at http://www.jdao-journal.org or http.
Conflicts of interest declared by the author: NONE Article received: 01-2012. Accepted for publication: 09-2012. 
development of periodontal infections and their delayed diagnosis explains the high prevalence of severe periodontitis ${ }^{1,6-8}$.

These considerations more than justify performing a periodontal examination each and every time a patient comes in for a dental consultation.

Unfortunately, the traditional method used for diagnosis, that is still recommended today, is thorough, complete and tedious ${ }^{4,5}$. From the start, in an exacting manner, with tooth by tooth inspection, the diagnosis seeks to identify various clinical factors, to locate lost attachments and any tooth mobility, to measure the depth of the periodontal pockets, the gingival recessions, the height of the keratinized gingiva ${ }^{2,3}$...Collecting all this data is impractical in the context of total dentistry or orthodontics.

\section{1 - SCREENING METHOD}

The main purpose of this periodontal examination is to answer the question of whether or not there are any sites of infection that require periodontal management.

This assessment has three parts: the initial patient interview (medical history), the clinical oral examination and the radiological examination.

\section{1 - 1 - Medical history}

The patient interview makes it possible to:

- target the risk factors for periodontal diseases ${ }^{11,16}$;
Besides, the new methods for diagnosis, based on the use of electronic probes, biological dosage for different markers of periodontal disease or even techniques using advanced imaging, still do not make it feasible to draw clinical conclusions that are pertinent ${ }^{18,19}$. Finally, periodontal screening is never mentioned, even though it informs future therapy choices.

Periodontal screening should become a standard practice since it is intended to identify patients at risk and to eliminate reservoirs of bacteria at an early stage.

The objective of this article is to offer a simplified and reasonable approach for periodontal disease screening that should be a routine part of each and every oral examination.

- determine the risk for PD as it relates to the general health of the patient: complications such as infections, hemorrhaging or scarring before the initiation of treatment. The examiner should pay special attention to the capacity of the immune responses of the patient;

- make patients become more aware of PD by questioning them about the symptoms of their chronic disease ${ }^{12}$.

A medical questionnaire specifically designed for PD screening will optimize time spent interviewing the patient. 


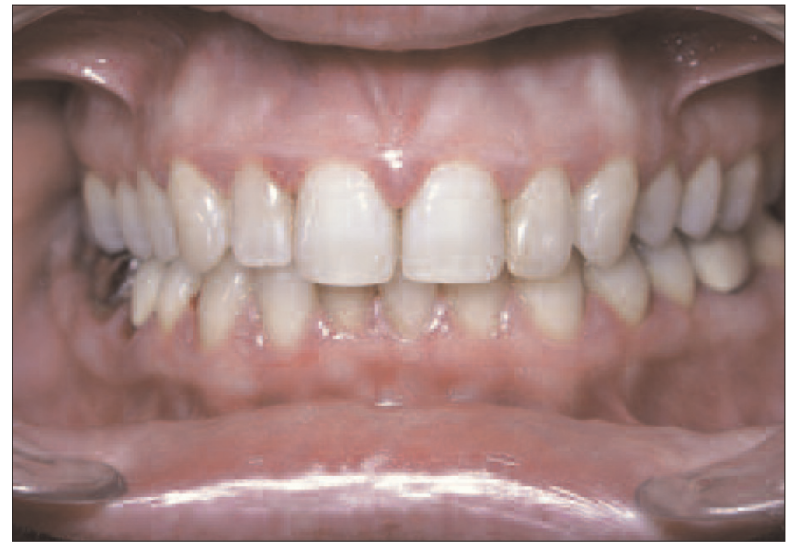

Figure 1

Gingivitis.

\section{1 - 2 - Clinical examination}

It is based on a binary method. At this point, the practitioner does not focus on the intensity of the clinical signs but whether or not there are signs of periodontal disease. It is divided into four stages: inspection, gingival palpation, dental palpation and probing.

\section{- Inspection}

The practitioner is looking for areas of erythema and edema mainly in the papillae (Figs. 1 and 2), as well as the presence of dental plaque.

\section{- Gingival palpation}

Oral gingival palpation from apical to coronal on all the teeth makes it possible to express the exudate contained in the periodontal pocket and/or to reveal the presence of blood and pus, markers of activity $^{10}$ (Figs. 3 and 4).

\section{- Dental palpation}

Dental palpation makes it possible to evaluate the stages of tooth mobil-

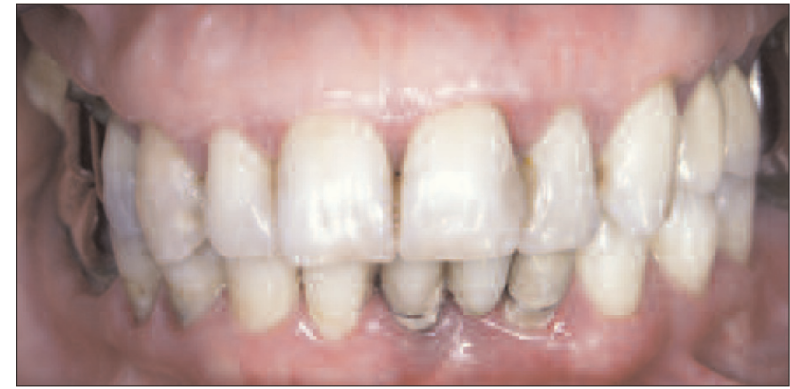

Figure 2

Inflammed areas characteristic of active periodontitis.

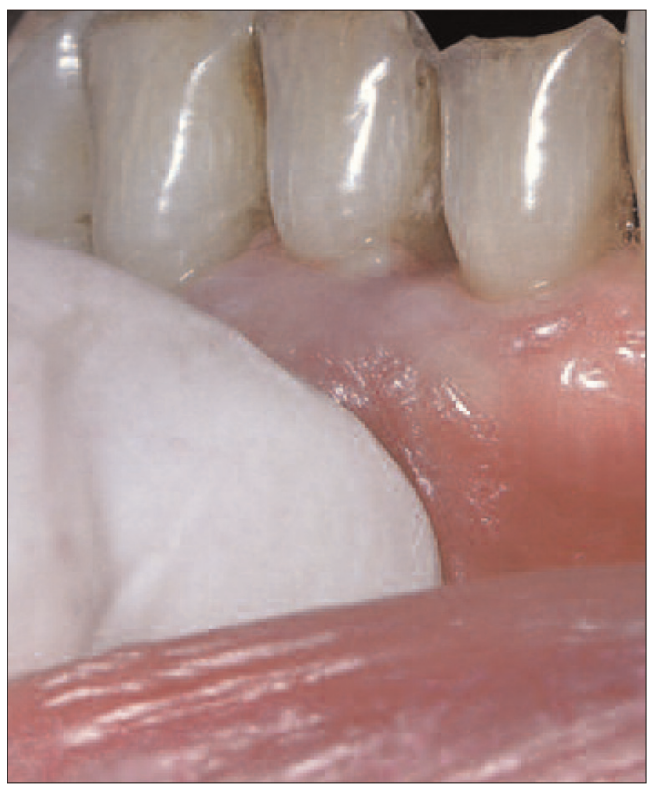

Figure 3

Digital pressure from the apical to coronal areas makes it possible to reveal the presence of pus.

ity that are markers for the severity of bone lysis ${ }^{15}$.

It is important to emphasize that the absence of the signs and symptoms previously described does not allow the examiner to exclude the presence of periodontal pockets (progressive periodontal disease) (Fig. 5). 

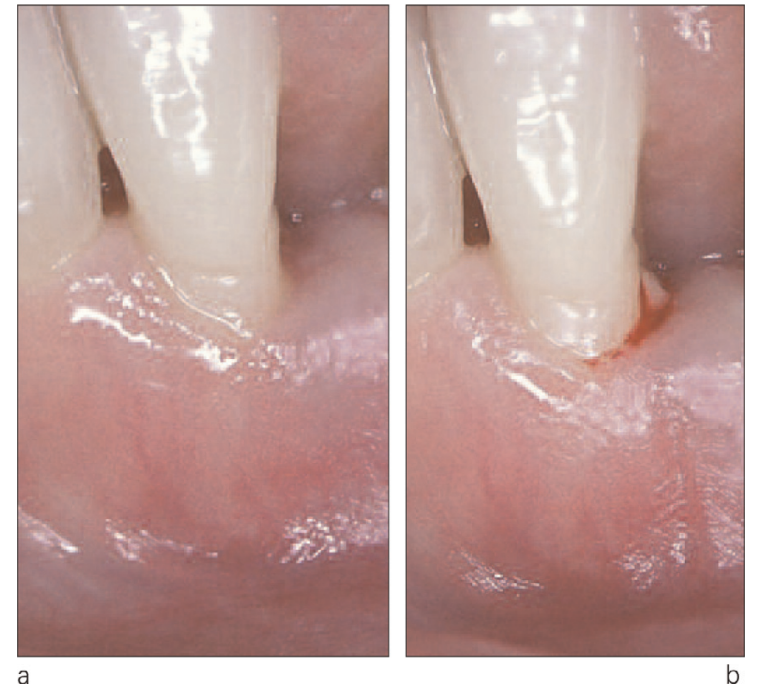

Figures $4 a$ and $4 b$

Clinical images of periodontitis before (a) and after palpation (b).

\section{- Probing}

At this stage, "detection probing" is the only examination that makes it possible to validate the presence of periodontal pockets.
Unlike conventional periodontal charting ${ }^{13,14}$, , periodontal detection probing is performed starting with the very first office visit using the same CP15 Hu-Friedy ${ }^{\circledR}$ probe. But, the focus is not on the probe values or even on the location of the infected sites. Working from a binary mode and using the depth scale measurements, the practitioner can determine whether or not there are pockets. Three stages can present: $<4 \mathrm{~mm}$, between 4 and $6 \mathrm{~mm},>6 \mathrm{~mm}$.

During the examination, the practitioner methodically probes the six points of each tooth with the CP15 Hu-Friedy ${ }^{\circledR}$ probe. The absence of periodontal infection is validated by the total absence of pockets.

Conversely, as soon as the examination shows evidence that there are periodontal pockets on at least four teeth, the examiner stops the probing because the test results are assuredly positive for the presence of periodontal disease.

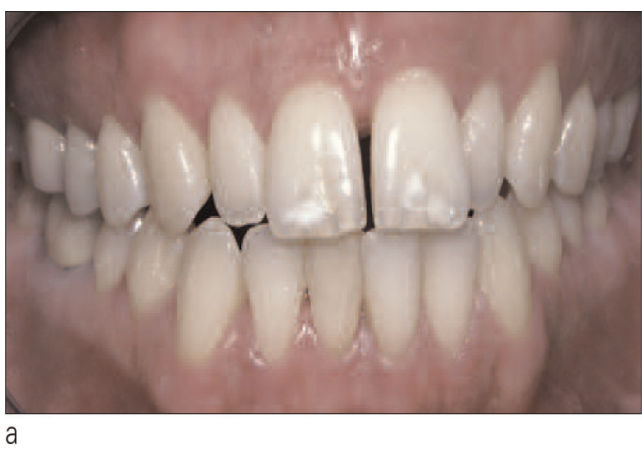

Figures $5 a$ and $5 b$

a: image of progressive periodontitis: absence of inflammatory signs;

b: radiological image: demonstrating bone loss. The clinical oral picture is deceptive since there are few signs of inflammation and the gingiva have a very coronary border.

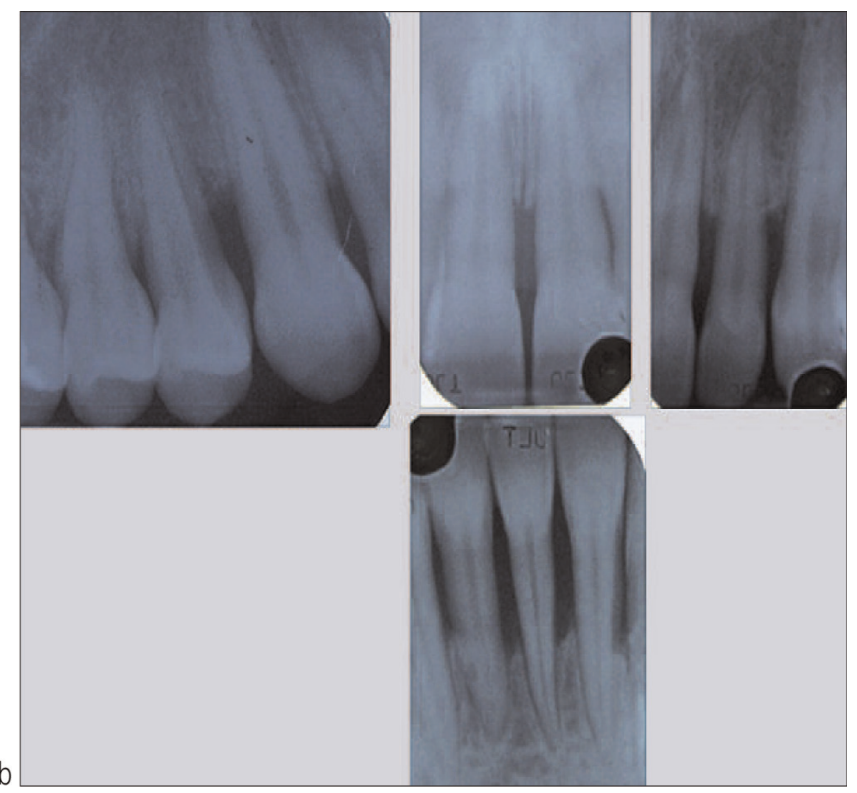




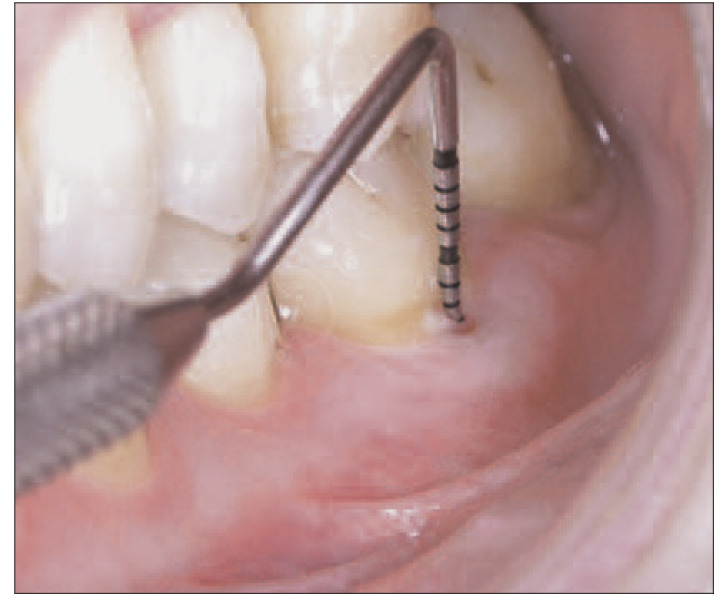

Figure 6

Detecting pockets while probing is the pathognomonic sign of periodontal disease.

\section{1 - 3 - Radiological examination}

It demonstrates the bone loss but does not detect whether or not there are reservoirs of periodontal infection ${ }^{9}$.

The radiological examination completes the detection probing and allows the practitioner to make a factbased diagnosis. A digital panoramic examination is recommended at this stage $^{17}$. It offers the advantage of being simple and quick. Since it is reproducible, it presents an overall and multidisciplinary view of the oral cavity. If need be, this examination can be completed with periapical films.

\section{2 - CLINICAL SYNTHESIS}

The data gathered thus far provides a solid basis for rating the patient according to the following categories: no periodontal disease, stabilized periodontal disease, peri-

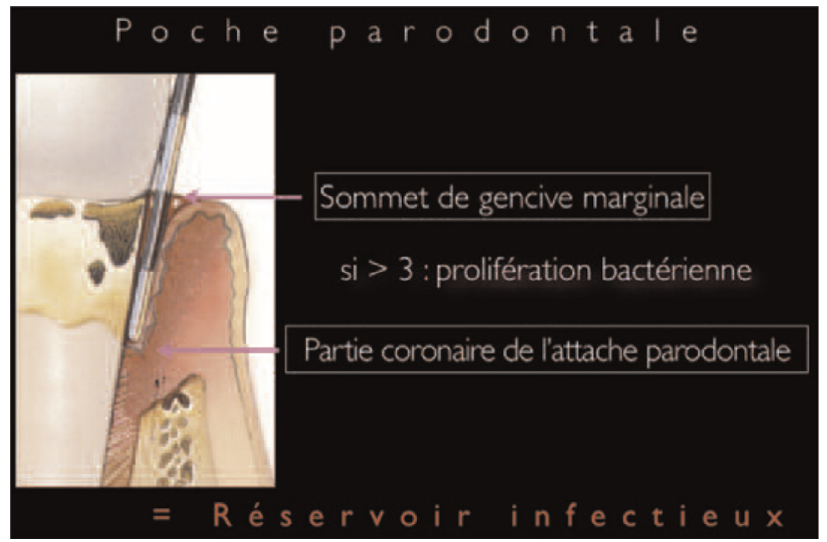

Figure 7

For $a=4 \mathrm{~mm}$ probing, the biofilm can no longer be treated by improved patient hygiene because now, there is a reservoir of periodontal infection.

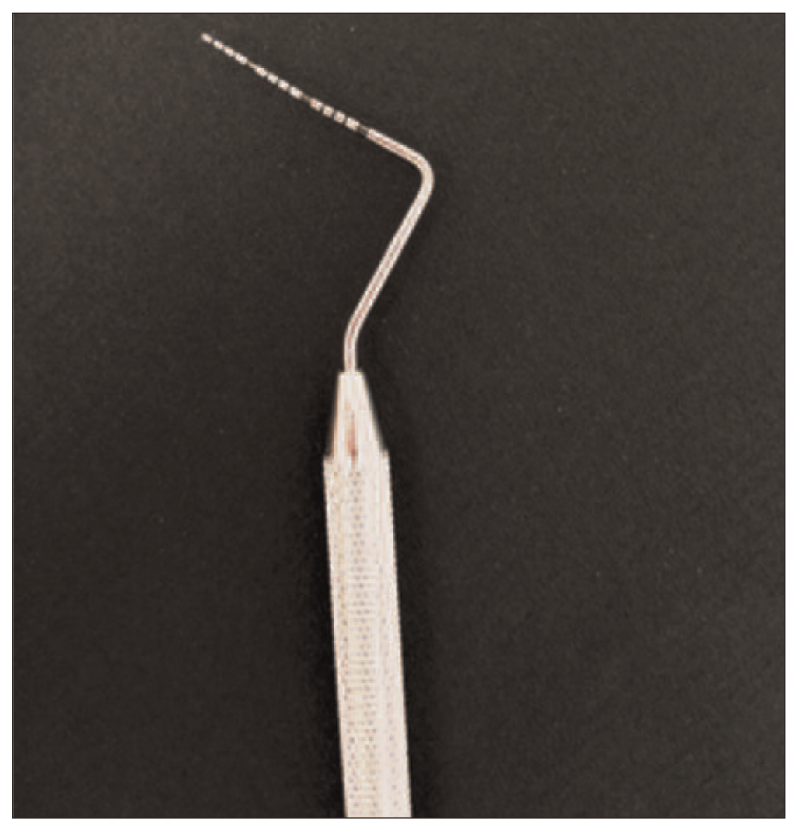

Figure 8

The CP15 Hu-Friedy ${ }^{\circledR}$ probe.

odontal disease with progressive gingivitis or marginal/moderate periodontitis, and finally, severe progressive periodontitis (Tab. I). 


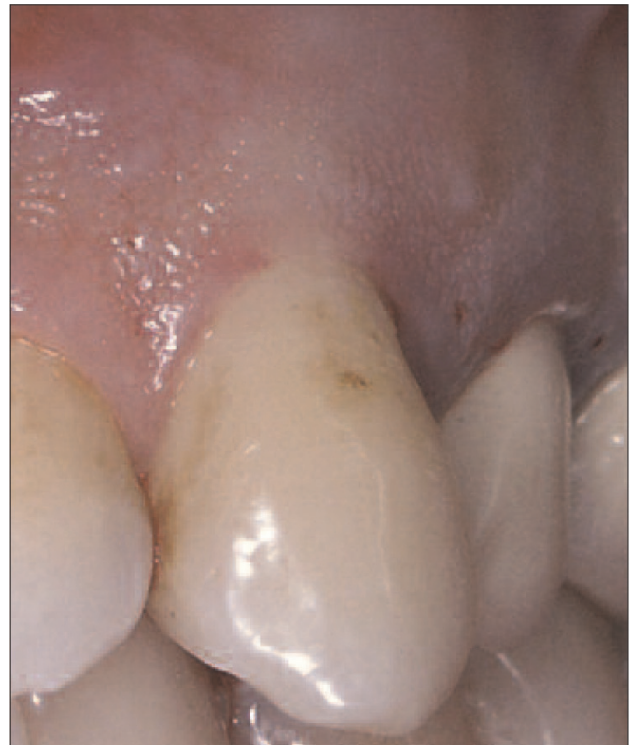

a

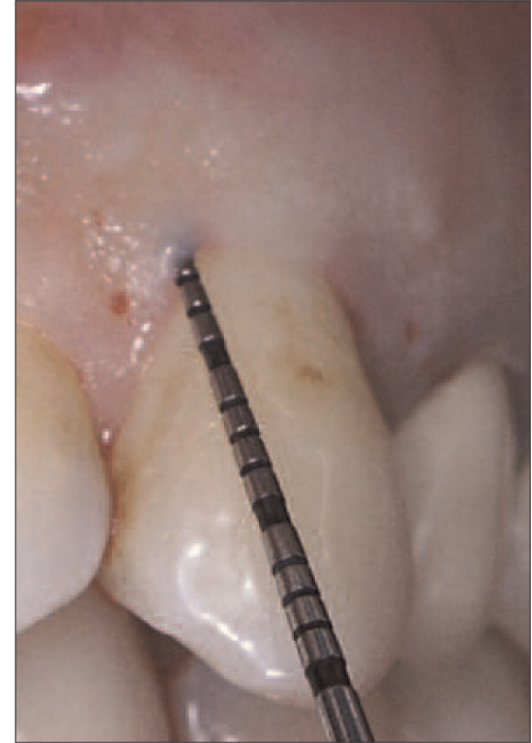

b

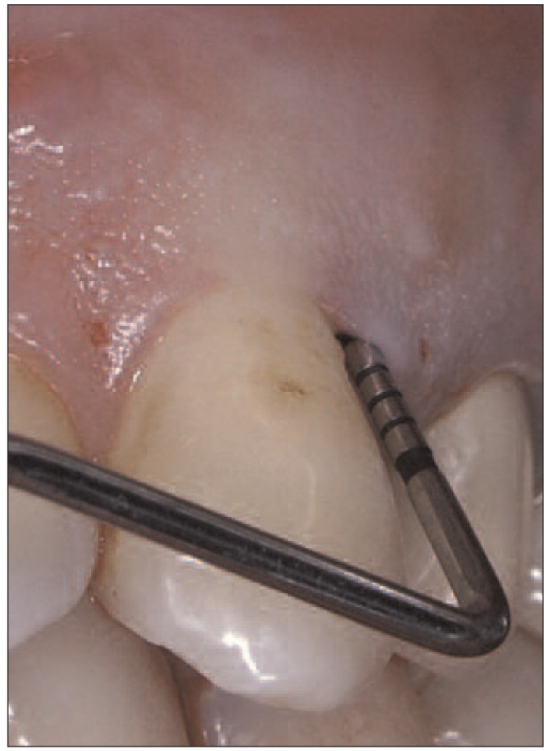

C

Figures 9a to $9 c$

Periodontal disease is a disease of site(s). Therefore, the examiner must probe 3 points on each face of the tooth. On the 23 shown here, the infectious reservoir is only found on the distal surface.

- The absence of periodontal disease is characterized by the absence of inflammatory signs, of pockets greater that $4 \mathrm{~mm}$ and bone loss. Therefore, the practitioner does not need to consider treatment. However, if dental plaque is present, the orthodontist should proceed with prophylactic cleaning (Fig. 10).

- Stabilized periodontal disease is characterized by the absence of inflammatory signs, the absence of pockets $=4 \mathrm{~mm}$, the presence of bone loss. The practitioner should set up supportive periodontal treatment (Fig. 11).

- Progressive periodontal disease with gingivitis or marginal/moderate periodontitis is characterized by the presence of inflammatory signs and/or probing values of 4 to $5 \mathrm{~mm}$, with little or no bone loss (Fig. 12). For this category, the prognosis for preserving the teeth is favorable but periodontal cleaning must be performed.

- Progressive periodontal disease with severe periodontitis is characterized by the presence of possible signs of inflammation, by probing values $4 \geq 6 \mathrm{~mm}$ and by severe bone loss. For this category, since the prognosis for preserving the teeth is uncertain, a periodontal cleaning should be performed as soon as possible (Fig. 13).

If the initial periodontal diagnosis turns out to be positive (last three categories), it will be followed later by a consultation so that the practitioner can explain the disease, discuss the treatment procedures and demonstrate techniques for plaque 


\begin{tabular}{|c|c|c|c|c|}
\hline & $\begin{array}{l}\text { Inflammatory } \\
\text { Signs }\end{array}$ & Pockets & $\begin{array}{l}\text { Radiological } \\
\text { bone loss }\end{array}$ & $\begin{array}{l}\text { Therapeutic } \\
\text { consequences }\end{array}$ \\
\hline $\begin{array}{l}\text { Healthy } \\
\text { periodontium }\end{array}$ & - & - & - & $\begin{array}{l}\text { No periodontal } \\
\text { treatment }\end{array}$ \\
\hline $\begin{array}{l}\text { Stabilized periodontal } \\
\text { disease }\end{array}$ & - & - & + & $\begin{array}{l}\text { Supportive periodontal } \\
\text { treatment }\end{array}$ \\
\hline
\end{tabular}

Table 1

This collection of data (inflammatory signs, depth of pockets and bone loss) helps the examiner categorize patients into four types and each calls for a different treatment.

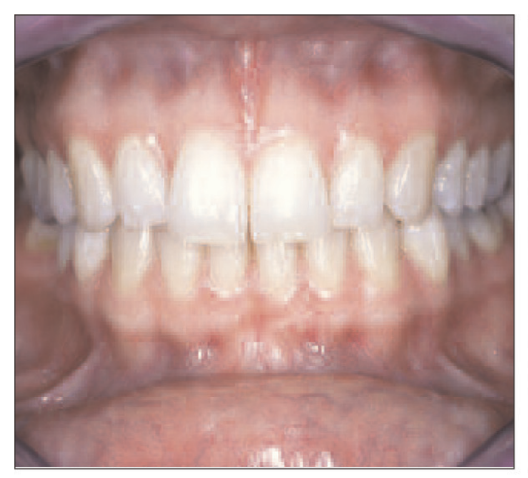

a

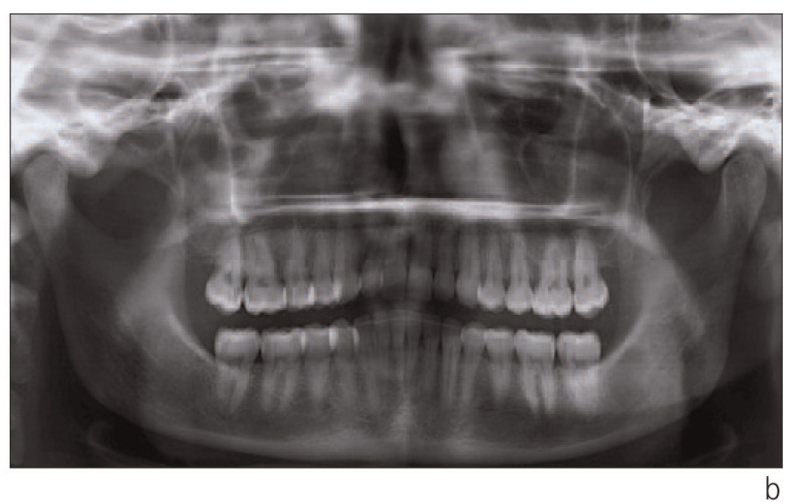

Figures $10 a$ and $10 b$

Patient with no periodontal disease: clinical view (a) and radiographic view (b). control that are individualized for the patient.

Immediately following this periodontal consultation, the practitioner has to manage the psychological aspects of this disease because its chronic nature can lull the patient into becoming less vigilant about controlling plaque.

In the case of progressive periodontal diseases (last two categories), the patient must receive a thorough periodontal diagnosis in order to plan appropriate treatment. 


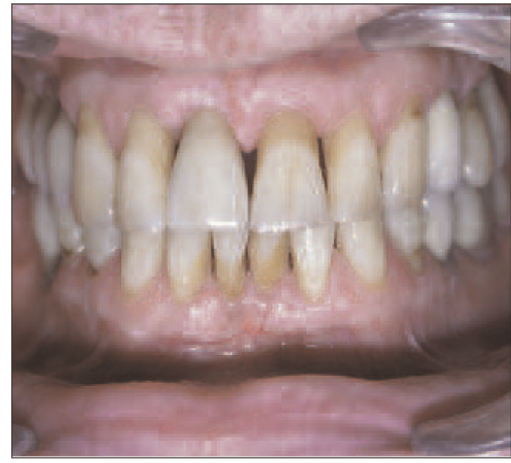

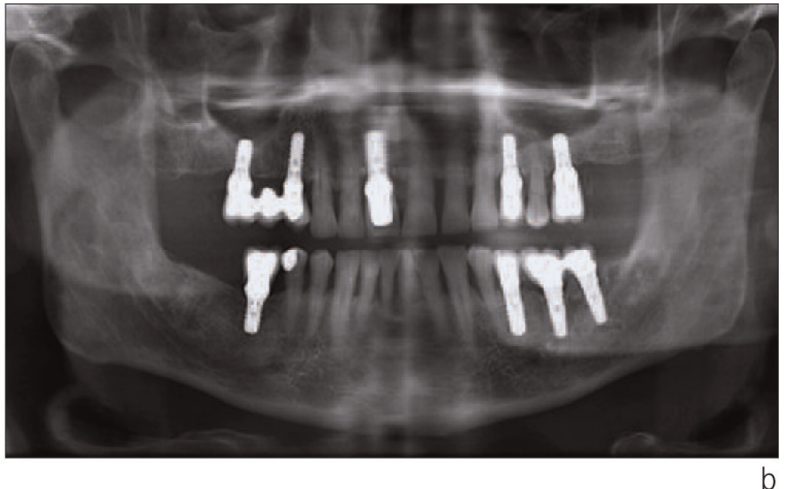

Figures $11 \mathrm{a}$ and $11 \mathrm{~b}$

Patient presenting stabilized periodontal disease: clinical view (a) and radiographic view (b).

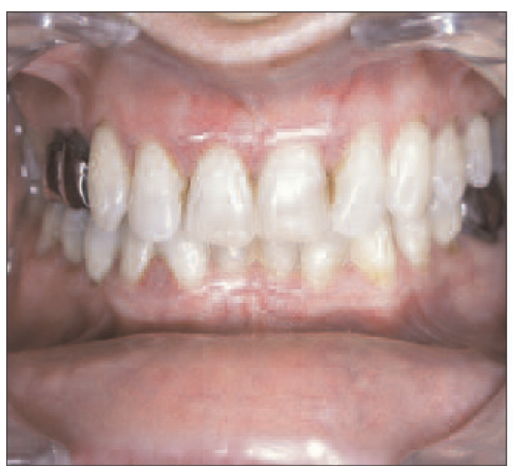

a

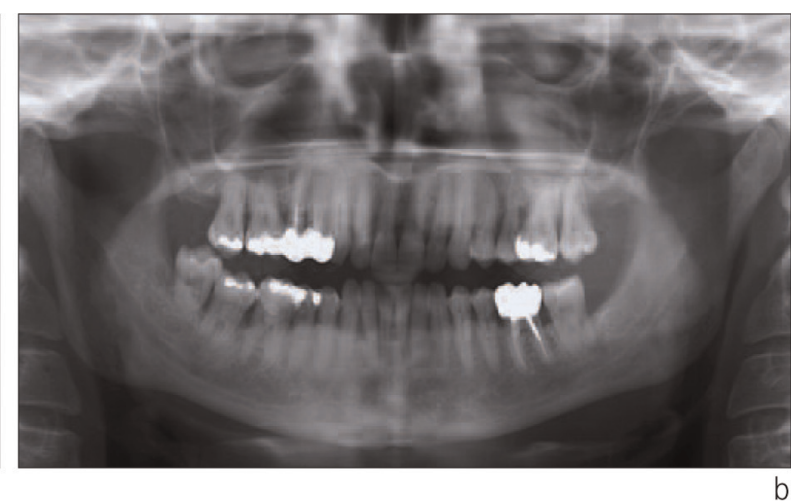

Figures $12 a$ and $12 b$

Patient presenting progressive periodontal disease with marginal periodontitis while mouth breathing: clinical view (a) and radiographic view (b).

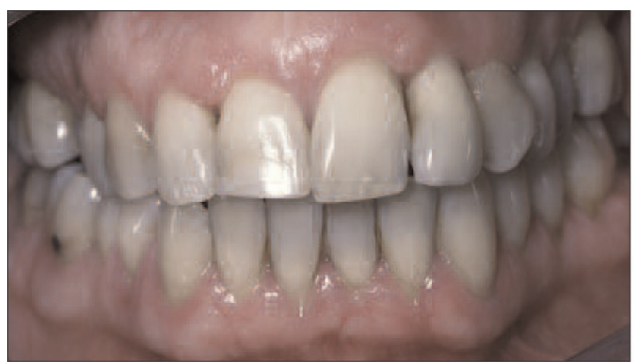

a

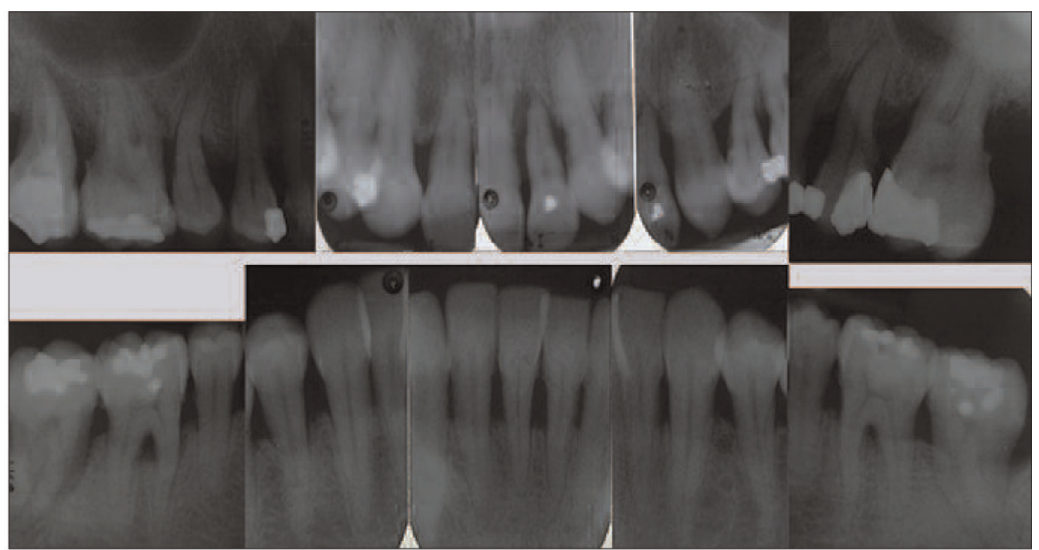

Figures $13 a$ and $13 b$

Patient presenting progressive periodontal disease with severe periodontitis: clinical view (a) and radiographic view (b). 


\section{$3-$ CONCLUSION}

The method for detection of periodontal disease that is described in this article incorporates all the classic stages of any diagnostic process: interview, clinical oral examination followed by a radiological examination.

The detection probing with a dental probe must be done routinely and systematically and given the highest priority in order to avoid delayed treatment that can occur if PD goes unnoticed by the patient and the unenlightened dentist.

Periodontal screening cannot show in an overly detailed manner, the stage of periodontal disease for every tooth but using the binary approach, it does make it possible to assert whether or not there is an infection and to quickly begin treatment.

Both orthodontists and dentists are licensed to perform this examination. It makes it possible to make a diagnosis, to begin periodontal management of the patient or to refer the patient to an appropriate specialist.

The examination should be repeated before any orthodontic treatment or prior to any functional reconstruction in order to maintain periodontal stability.

\section{REFERENCES}

1. Albandar JM, Rams TE. Global epidemiology of periodontal diseases: an overview. Periodontol 2000 2002;29:7-10.

2. American Academy of Periodontology. Diagnosis of periodontal diseases: position paper. J Periodontol. 2003;74(8):1237-47.

3. American Academy of Periodontology. Comprehensive periodontal therapy: a statement by the American Academy of Periodontology. J Periodontol 2011:82(7):943-9.

4. Armitage GC. Diagnosing periodontal diseases and monitoring the response to periodontal therapy. In: Perspectives on oral antimicrobial therapeutics. Littleton, MA: PSG Publishing Co., 1987:47-60.

5. Armitage GC. The complete periodontal examination. Periodontology 2000 2004; 34:22-33.

6. Bouchard P, Boutouyrie P, Mattout C, Bourgeois D. Risk assessment for severe clinical attachment loss in an adult population. J Periodontol 2006;77(3):479-89.

7. Bourgeois D, Baehni P. Surveillance, épidémiologie et maladies parodontales. Encycl Med Chir (Elsevier SAS Paris) 2002;23-444-A-10.

8. Bourgeois D, Bouchard P, Mattout C. Epidemiology of periodontal status in dentate adults in France, 2002-2003. J Periodontal Res 2007;42(3):219-27.

9. Brägger U. Radiographic parameters: biological signifiance and clinical use. Periodontology 2000 2005:39:73-90.

10. Claffey N, Egelberg J. Clinical indicators of probing attachment loss following initial periodontal treatment in advanced periodontitis patients. J Clin Periodontol 1995;22(9):690-6.

11. Genco RJ. Current view of risk factors for periodontal diseases. J Periodontol 1996;67(10 Suppl):1041-9.

12. Godard A, Dufour T, Jeanne S. Application of self-regulation theory and motivational interview for improving oral hygiene: a randomized controlled trial. J Clin Periodontol 2011;38(12):1099-105. 
13. Greenstein G. Comtemporary interpretation of probing depth assessments: diagnostic and therapeutic implications. J Periodontol 1997;68(12):1194-205.

14. Mombelli A. Clinical parameters: biological validity and clinical utility. Periodontology 2000 2005;39:30-9.

15. Mühlemann HR. Tooth mobility: a review of clinical aspects and research findings. J Periodontol 1967;38(6) Suppl:686-713.

16. Nunn ME. Understanding the etiology of periodontitis: an overview of periodontal risk factors. Periodontol 2000 2003;32:11-23.

17. Persson RE, Tzannetou S, Feloutzis AG, Brägger U, Persson GR, Lang NP. Comparison between panoramic and intraoral radiographs for the assessment of alveolar bone levels in a periodontal maintenance population. J Clin Periodontol 2003;30(9): 833-9.

18. Wolf DL, Lamster IB. Contemporary concepts in the diagnosis of periodontal disease. Dent Clin North Am 2011;55(1):47-61.

19. Xiang X, Sowa MG, lacopino AM, Maev RG, Hewko MD, Man A, Liu KZ. An update on novel noninvasive approaches for periodontal diagnosis. J Periodontol. 2010;81(2):186-98. 